\title{
Análise de metodologias de pesquisa sobre utilização de assentos de segurança infantil: lições de um projeto piloto
}

\author{
Analysis of research methodologies about the use of child restraint systems: lessons of a pilot project
}

\author{
Sergio Ricardo L. de Oliveira1', Maria Dalva de B. Carvalho², Rosângela Getirana Santana³, Camila Hibari Kawazoe, \\ Eduardo Quirino dos Santos ${ }^{4}$, Fernanda Cabrera de Oliveira ${ }^{4}$
}

\section{RESUMO}

Objetivo: Analisar metodologias de pesquisa sobre a utilização de assentos de segurança infantil.

Métodos: Quatro metodologias de pesquisa foram aplicadas, a fim de verificar o uso de assentos para transporte infantil em veículos que levavam crianças menores de quatro anos a uma creche, durante um dia letivo: inspeção sem entrevista, inspeção com entrevista, questionário auto-aplicativo e filmagem digital. As metodologias foram analisadas quanto à aceitação por parte dos sujeitos de pesquisa, capacidade de obtenção de dados e concordância de dados captados por instrumentos distintos. Aplicouse análise de concordância (coeficiente de Kappa) para avaliar a homogeneidade dos dados obtidos pelas diversas metodologias.

Resultados: Foram observados 56 veículos, $75 \%$ deles com filmagem. O retorno do questionário auto-aplicado ocorreu em $70 \%$. A capacidade de captação de dados foi de $99 \%$ para inspeção sem entrevista, $97 \%$ para inspeção com entrevista e $84 \%$ para filmagem digital. A inspeção sem entrevista mostrou-se mais concordante com os dados filmados.

Conclusões: $\mathrm{O}$ alto índice de retorno do questionário autoaplicável pode ter sido favorecido pelas características da população estudada. A filmagem mostrou-se inadequada por questões éticas e técnicas, além de considerável índice de recusa; porém, foi útil para indicar a confiabilidade da inspeção sem entrevista em relação ao local de assento das crianças. Detectou-se falha dos instrumentos em captar o gênero dos ocupantes dos veículos. Altos índices de captação de dados atestaram a aptidão das metodologias de inspeção com e sem entrevista para explorar a utilização de assentos de segurança infantil.

Palavras-chave: acidentes de trânsito; assentos de segurança infantil; dispositivos de retenção infantil.

'Pediatra intensivista, mestre em Ciências da Saúde pela Universidade Estadual de Maringá (UEM), Maringá, PR, Brasil

${ }^{2}$ Professora-associada do Programa de Pós-graduação em Ciências da Saúde da UEM, Maringá, PR, Brasil

${ }^{3}$ Professora adjunta do Departamento de Estatística da UEM, Maringá, PR, Brasil

${ }^{4}$ Acadêmicos do curso de Medicina da UEM, Maringá, PR, Brasil

\section{ABSTRACT}

Objective: Analyze research methodologies about the utilization of child restraint systems.

Methods: In order to verify child restraint systems used in vehicles that transported children up to four years old to one day care center, during a single study day, four methods were applied: inspection without interview, inspection with interview, self-applied questionnaire and digital filming. These methods were analyzed regarding their acceptance by research subjects, their ability to retrieve data and regarding agreement of the data recovered by the different tools, according to Kappa coefficient.

Results: Fifty-six vehicles were observed $-75 \%$ of them by filming. The rate of return of the self-applied questionnaire was $70 \%$. The ability to recover data was $99 \%$ for inspection without interview, $97 \%$ for inspection with interview and $84 \%$ for digital filming. Inspection without interview had the better agreement towards digital filming for data retrieving.

Conclusions: The high index of self-applied questionnaire return may be related to characteristics of the studied population. Filming was not suitable due to ethical and technical reasons and considering the high refusal rate, but it was useful to show agreement with inspection without interview of infant retaining device placement. The tools failed to identify the gender of the passengers. The high index of the data recover indicates the ability of the inspection methodologies to explore the use of child restraint system.

Key-words: accidents, traffic; infant equipment; child restraint system.
Endereço para correspondência:

Sergio Ricardo L. de Oliveira

Rua Mem de Sá, 1.899, casa 5 - Vila Bosque

CEP 87005-010 - Maringá/PR

E-mail: srloliveira@gmail.com

Recebido em: 3/12/2007

Aprovado em: 19/3/2008 


\section{Introdução}

Os acidentes apresentam crescente destaque no perfil de mortalidade no Brasil, como tem ocorrido em países desenvolvidos. As diversas formas de violência são as maiores responsáveis pelos anos potenciais de vida perdidos e constituem a principal causa de morte a partir do primeiro ano de vida ${ }^{(1,2)}$. Para minimizar as mortes e as possíveis seqüelas de crianças passageiras de automóveis, existem os consagrados dispositivos de retenção infantil ou assentos de segurança infantil (ASI), com suas normas de utilização que, quando adequadamente aplicadas, reduzem em $71 \%$ a chance de morte ${ }^{(3-5)}$.

Embora o uso de ASI seja obrigatório por lei em diversos países, inclusive no Brasil ${ }^{(6,7)}$, dados internacionais apontam freqüente negligência, observando-se o não uso e o uso errôneo ${ }^{(8)}$. Os artigos nacionais relacionados aos ASI são recentes ${ }^{(9,10)}$, sendo este um assunto inexplorado em nosso meio, ao contrário do observado no contexto dos países mais desenvolvidos. Não há dados brasileiros publicados quanto ao uso de ASI nem metodologia nacional descrita para obtenção de tais dados.

Vários artigos internacionais apresentam diferentes metodologias de pesquisa quanto à utilização de ASI. Os locais de coleta de dados mais empregados foram as vias públicas de acesso a escolas $^{(8,11-14)}$, estacionamentos de lanchonetes ${ }^{(11,14-16)}$ e estacionamentos de mercados ${ }^{(8,11)}$. Simpson $e$ et ${ }^{(17)}$ testaram quatro metodologias de pesquisa: inspeção sem entrevista, inspeção com entrevista, questionários auto-aplicáveis e entrevista em grupo. A inspeção com entrevista se mostrou como instrumento de grande capacidade de captação de dados e de fácil aplicação em larga escala. Os questionários auto-aplicáveis são passíveis de múltiplos vieses e variados índices de retorno, o que pode comprometer sua aplicação em diversas populações ${ }^{(18)}$.

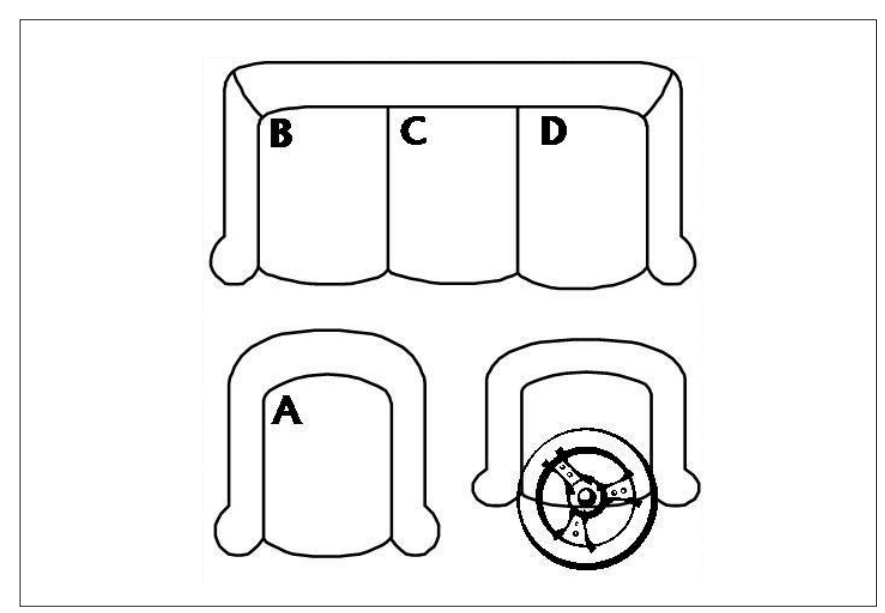

Figura 1 - Representação esquemática do automóvel.
O objetivo deste artigo, baseado em um projeto piloto, foi analisar metodologias destinadas a explorar a utilização de ASI por crianças menores de quatro anos de idade, testando instrumentos e observadores.

\section{Métodos}

Estudo observacional transversal de veículos que transportavam crianças a uma creche privada da cidade de Maringá, Paraná. A creche escolhida para a execução do projeto piloto atendia apenas a funcionários da universidade à qual o projeto estava vinculado. Por estarem no campus universitário, as vias de acesso à creche favoreceriam a aplicação das metodologias propostas.

Utilizando um banco de fotos, observadores foram treinados para reconhecer os diversos tipos de ASI e seu local de instalação no veículo. Além disso, entrevistas simuladas serviram para padronizar a abordagem aos condutores dos veículos. Durante um dia letivo, foram observados os carros que transportavam crianças à creche. A observação ocorreu na via de acesso ao estacionamento da creche durante duas horas pela manhã (das 7 às 9 horas) e duas horas pela tarde (das $12 \mathrm{~h} 30$ às 14h30), correspondendo aos períodos de chegada das crianças.

Foram aplicadas simultaneamente quatro metodologias de pesquisa: inspeção com entrevista, inspeção sem entrevista, questionário auto-aplicativo e filmagem digital. $\mathrm{Na}$ inspeção com entrevista, um observador abordava o motorista no momento da entrada no estacionamento. Com o automóvel parado, o observador apresentava a pesquisa, o termo de consentimento e rapidamente aplicava o Questionário 1, composto por representação esquemática dos locais de assento de um carro (Figura 1). O observador, para cada assento, anotava a respeito da utilização de cinto de segurança pelo adulto, a idade e o peso das crianças e indicava os assentos sem passageiros. Ao final de sua entrevista, o observador apresentava o questionário auto-aplicável, que deveria ser devolvido à creche . Tal questionário, composto por questões estruturadas e semiestruturadas, explorava características das crianças quanto a gênero, idade e peso, aspectos socioeconômicos e demográficos das famílias, além de conhecimentos específicos sobre a utilização de ASI. Na inspeção sem entrevista, outro observador, simultaneamente ao primeiro, respondia ao Questionário 2. Tal questionário utilizava o mesmo esquema de localização de assentos do Questionário 1, sendo estruturado para que o observador assinalasse a utilização de cintos de segurança por adultos e de ASI por crianças. Todos os questionários foram identificados pela placa do veículo. 
Com o intuito de aferir a veracidade das observações realizadas pelas metodologias de inspeção, foi feita a filmagem com duas câmeras digitais operadas por cinegrafistas profissionais. Respeitando o direito a privacidade de imagem, uma carta de consentimento foi enviada aos pais na véspera da coleta de dados. Tal carta não explicava o motivo das filmagens, nem os objetivos da pesquisa, assegurando apenas a razão científica da filmagem, além de garantir que maiores informações estariam disponíveis no momento da pesquisa. Junto à carta, foram encaminhados cartões de identificação nas cores vermelha e verde. Caso consentisse em ter seu veículo filmado, os pais deveriam pendurar o cartão verde no espelho retrovisor do condutor. Do contrário, deveriam pendurar o cartão vermelho. Para minimizar omissões quanto ao uso do cartão, a carta foi enviada por duas vezes consecutivas, nos dois dias precedentes à coleta de dados. Uma mensagem de aviso foi veiculada repetidamente na rádio universitária local na véspera da coleta e banners solicitando a sinalização quanto à filmagem foram espalhados nas vias de acesso à creche, horas antes do início da coleta. Ao observar a aproximação de um veículo com cartão vermelho, os cinegrafistas interrompiam a filmagem. A presença do cartão vermelho, entretanto, não impedia a abordagem pelos observadores. Diante do cartão verde, as filmagens eram iniciadas pelas placas dos veículos e, posteriormente, focalizavam o motorista e os passageiros.

Para aumentar o retorno do questionário auto-aplicável, todo o projeto piloto recebeu formatação visual criada por agência de publicidade, incluindo logomarca em cores utilizada na carta enviada aos pais, no questionário auto-aplicável, nos banners de sinalização e nas camisetas utilizadas pelos observadores e funcionários da creche. Para lembrar a necessidade de devolução do questionário auto-aplicável, banners permaneceram na recepção da creche e funcionários usaram a camiseta do projeto durante uma semana. Decorrido este período, os pais foram convidados à palestra sobre normas de segurança para o transporte de crianças em automóveis.

Para a análise estatística dos dados foi utilizado o programa Statistica 7. O projeto recebeu autorização da direção da creche, tendo sido aprovado pelo Comitê de Ética em Pesquisa da Universidade Estadual de Maringá.

\section{Resultados}

Foram observados 56 veículos que transportavam, além dos 56 motoristas, 17 adultos e 67 crianças com idade entre cinco meses e oito anos. Das crianças, dez tinham idade de quatro anos ou mais, não sendo matriculadas na creche e, portanto, excluídas do processo de análise dos dados. Dos 56 motoristas, $42(75 \%)$ permitiram o procedimento de filmagem.

Avaliou-se a capacidade de captação de dados das metodologias de inspeção com e sem entrevista e filmagem digital, de acordo com a possibilidade de cada instrumento (Quadro 1). A quantidade de informações em cada veículo variou em função do número de passageiros e detalhes a respeito dos mesmos. Avaliando as falhas de registros, determinou-se que a capacidade de captação de dados dos instrumentos foi de 99\% para inspeção sem entrevista, $97 \%$ para inspeção com entrevista e $84 \%$ para filmagem. No entanto, ao concluir a tabulação dos dados, percebeu-se que as metodologias de observação não registraram o gênero do motorista nem dos passageiros.

Dos 56 questionários auto-aplicáveis entregues aos condutores, 39 foram devolvidos à creche, atingindo índice de retorno de $70 \%$. Por meio deste instrumento, foi possível determinar o perfil das famílias entrevistadas e o nível de conhecimento sobre os ASI. O perfil da população estudada era condizente à comunidade acadêmica na qual a creche estava inserida, com altos índices de escolaridade e renda

Quadro 1 - Informações passíveis de captação pelos diversos métodos

Inspeção com entrevista (Questionário 1)
Situação de restrição do motorista
Distribuição de adultos pelos assentos do veículo
Distribuição de crianças pelos assentos do veículo
Peso das crianças
Idade das crianças
Inspeção sem entrevista (Questionário 2)
Situação de restrição do motorista
Distribuição de adultos pelos assentos do veículo
Situação de restrição dos adultos
Distribuição de crianças pelos assentos do veículo
Situação de restrição das crianças
ASI escolhido
Direção de instalação das cadeirinhas
Presença de clip peitoral em cadeirinhas e
bebês-conforto
Filmagem digital (duas filmadoras simultâneas)
Situação de restrição do motorista
Distribuição de adultos pelos assentos do veículo
Situação de restrição dos adultos
Distribuição de crianças pelos assentos do veículo
Situação de restrição das crianças
ASI escolhido
Direção de instalação das cadeirinhas
Presença de clip peitoral em cadeirinhas e
bebês-conforto


(70\% dos entrevistados apresentavam pós-graduação e 46\%, renda acima de dez salários-mínimos).

Durante a tabulação dos dados, percebeu-se que, em $11 \%$ dos carros, houve discordância entre os observadores quanto à presença de passageiro nos assentos $\mathrm{B} e \mathrm{D}$, isto é, enquanto o primeiro observador (metodologia de inspeção com entrevista) determinava a presença do passageiro no assento $\mathrm{B}$, o segundo observador (metodologia de inspeção sem entrevista) registrava a presença do mesmo passageiro no assento $\mathrm{D}$ ou vice-versa. Com o intuito de determinar qual observador estava correto, calculou-se o coeficiente Kappa entre os observadores em relação às imagens da filmagem. O coeficiente Kappa entre o primeiro observador e as imagens foi considerado excelente (acima de $80 \%)^{(19)}$ em dois dos assentos. O coeficiente Kappa entre o segundo observador e as imagens foi considerando excelente em três dos quatro assentos, com índices de concordância superiores aos obtidos para o primeiro observador (Tabela 1).

\section{Discussão}

Apesar do bom índice de retorno do questionário autoaplicável (70\%), o seu emprego poderá dificultar a obtenção de dados na realização do projeto de pesquisa ao qual este piloto está vinculado, uma vez que, certamente, haverá diferença na escolaridade e renda da população alvo em relação à do presente projeto. Tais questionários tradicionalmente apresentam grandes falhas de retorno, comprometendo sua aplicação, de acordo com o perfil da população ${ }^{(18)}$. Projeto piloto semelhante ao aqui descrito e executado na Nova Zelândia obteve $59 \%$ de retorno espontâneo de um questionário auto-aplicável e esse índice atingiu $74 \%$ somente após contato telefônico ou postal com os entrevistados ${ }^{(17)}$. Tais procedimentos de contato posterior, além de exigirem identificação

Tabela 1 - Índice de concordância Kappa em relação a informações dos ocupantes do veículo aferidas pelo Observador 1 (inspeção com entrevista) e Observador 2 (inspeção sem entrevista), em comparação à filmagem digital

\begin{tabular}{lcccc}
\hline & \multicolumn{4}{c}{ Vídeo (índice Kappa em \%) } \\
\cline { 2 - 5 } & $\begin{array}{c}\text { Assento } \\
\text { A }\end{array}$ & $\begin{array}{c}\text { Assento } \\
\text { B }\end{array}$ & $\begin{array}{c}\text { Assento } \\
\text { C }\end{array}$ & $\begin{array}{c}\text { Assento } \\
\text { D }\end{array}$ \\
\hline $\begin{array}{l}\text { Observador 1 } \\
\text { versus filme }\end{array}$ & 94 & 71 & 90 & 80 \\
$\begin{array}{l}\text { Observador 2 } \\
\text { versus filme }\end{array}$ & 94 & 90 & 100 & 90 \\
\hline
\end{tabular}

${ }^{*}$ Concordâncias acima de 80\% são consideradas excelentes e, entre 60 e $80 \%$, boas $^{(13)}$ do entrevistado, ainda carecem de exploração quanto à sua inocuidade em relação aos dados obtidos e, por invadirem a privacidade, podem gerar coação e desconforto ${ }^{(20)}$.

A filmagem apresentou capacidade de captação de dados inferior à dos observadores, o que pode ser justificado por aspectos operacionais. Muitos veículos apresentavam películas protetoras nas janelas, aumentando o reflexo natural do vidro captado por câmeras, porém com pouca repercussão sobre o olho humano. Tal situação exigiu a abertura de portas e janelas, acrescentando à metodologia de filmagem maior intromissão. Mesmo assim, os ângulos de filmagem das filmadoras continuaram menos amplos do que o de observadores. $\mathrm{O}$ custo das filmagens, aliado às implicações éticas e técnicas, às falhas de captação e ao considerável índice de recusa $(25 \%)$ inviabilizam sua utilização em projeto mais amplos. No entanto, as imagens registradas, tidas como padrão-ouro, possibilitaram determinar que o segundo observador (responsável pela inspeção sem entrevista) era mais fidedigno do que o primeiro observador (responsável pela inspeção com entrevista) quanto à determinação do local de assento dos passageiros.

A divergência entre os observadores foi inerente ao ângulo de visão. O primeiro observador, por ter que se comunicar com o motorista, enxergava o veículo pelo lado do condutor. O segundo observador ficava do lado oposto do carro e dispunha de maior mobilidade. Além disso, o primeiro observador tinha mais tarefas a executar: comunicar-se com o motorista, oferecer o questionário auto-aplicável juntamente com o termo de consentimento, registrar a presença ou a ausência de passageiros no assento, além de obter idade e peso das crianças. O segundo observador apenas registrava a presença ou a ausência de passageiros e o modo de restrição dos mesmos. Responsável por menor número de tarefas, não surpreende que os índices de concordância do segundo observador em relação às imagens obtidas por filmagem sejam superiores aos demonstrados pelo primeiro observador. Deste modo, ficou estabelecido para o restante do projeto que, diante de divergências entre os observadores quanto à disposição dos passageiros, as informações registradas pelo segundo observador seriam consideradas corretas.

Concordante com dados internacionais, as metodologias de inspeção realizadas por observadores demonstraram boa aplicabilidade e excelentes resultados quanto à obtenção de $\operatorname{dados}^{(17)}$. Tais metodologias já foram aplicadas em diversos estudos sobre o uso de $\mathrm{ASI}^{(8,12-16)}$. A alta capacidade de captação de dados apresentada pela inspeção com e sem entrevista (97\% 
e $99 \%$, respectivamente) no presente projeto piloto reforça tais constatações. No entanto, ao final do estudo, detectou-se falha dos questionários utilizados para captar o gênero dos motoristas e das crianças, fator que poderia apresentar alguma influência quanto ao uso correto de ASI. Uma vez resolvida tal falha, espera-se excelente desempenho dos questionários e observadores envolvidos nas inspeções com e sem entrevista, tornado tais metodologias aplicáveis ao estudo exploratório sobre a utilização de ASI.

\section{Agradecimentos}

Agradecimentos à Sociedade Eticamente Responsável de Maringá (SER-Maringá).

\section{Referências bibliográficas}

1. Feliciano AB, Moraes AS. Demanda por doenças crônico-degenerativas entre adultos matriculados em uma unidade básica de saúde em São Carlos-SP. Rev Latino-Am Enfermagem 1999;7:41-7.

2. Barros MDA, Ximenes R, Lima MLC. Mortalidade por causas externas em crianças e adolescentes: tendências de 1979 a 1995. Rev Saude Publica 2001;35:142-9.

3. Lund UJ. The effect of seating location on the injury of properly restrained children in child safety seats. Accid Anal Prev 2005;37:435-9.

4. Winston FK, Durbin DR, Kallan MJ, Moll EK. The danger of premature graduation to seat belts for young children. Pediatrics 2000;105:1179-83.

5. Arbogast KB, Durbin DR, Cornejo RA, Kalan MJ, Winston FK. An evaluation of effectiveness of forward facing child restraint systems. Accid Anal Prev 2004;36:585-9.

6. Brasil - Ministério das Cidades - Denatran [homepage on the Internet]. Código de Trânsito Brasileiro. Lei n 9.503, de 23 de setembro de 1997. Capítulo III - das normas gerais de circulação e conduta. Artigos 64 e 65 [cited 2008 March 11]. Available from: http://www.denatran.gov.br/ctb.htm

7. Brasil - Ministério das Cidades - Denatran [homepage on the Internet]. Resolução 15/98; dispõe sobre o transporte de menores de 10 anos e dá outras providências [cited 2008 March 11]. Available from: http://www.denatran.gov. $\mathrm{br} / \mathrm{download} /$ Resolucoes/resolucao015_98.doc

8. Decina LE, Lococo KH. Child restraint system use and misuse in six states. Accid Anal Prev 2005;37:583-90.

9. Waskman RD, Pirito RMBK. O pediatra e a segurança no trânsito. J Pediatr (Rio J) 2005:81:181-8.
10. Oliveira SRL, Carvalho MDB, João PRD. Normas de segurança para o transporte de crianças em automóveis. Pediatria (São Paulo) 2007:29;129-43.

11. Eby DW, Kostyniuk LP, Vivoda JM. Restraint use patterns for older child passengers in Michigan. Accid Anal Prev 2001;33:235-42.

12. Edgerton EA, Duan N, Seidel JS, Asch S. Predictors of seat-belt use among school-aged children in two low-income Hispanic communities. Am J Prev Med 2002;22:113-6.

13. Ebel BE, Koepsell TD, Bennett EE, Rivara FP. Too small for seatbelt: predictors of booster seat use by child passengers. Pediatrics 2003;111:e323-7.

14. Brewin M, Peters T. An investigation of child restraint/seatbelt usage in motor vehicles by Maori in Northland New Zealand. Inj Prev 2003;9:85-6.

15. Moeller S, Berger L, Salvador JG, Helitzer D. How old is that child? Validating the accuracy of age assignments in observational surveys of vehicle restraint use. Inj Prev 2002;8:248-51.

16. Greenberg-Seth J, Hemenway D, Gallagher SS, Lissy KS, Ross JB. Factors associated with rear seating of children in motor vehicles: a study in two low-income, predominantly Hispanic communities. Accid Anal Prev 2004;36:621-6.

17. Simpson JC, Wren J, Chalmers DJ, Stephenson SCR. Examining child restraint use and barriers to their use: lessons from a pilot study. Inj Prev 2003;9:326-31.

18. Bowling A. Mode of questionnaire administration can have serious effects on data quality. J Public Health 2005;27:281-91.

19. Jekel JF, Katz DL, Elmore JG, editores. Epidemiologia, bioestatística e medicina preventiva. $2^{\mathrm{a}}$ ed. Porto Alegre: Artmed; 2005. p.114-28.

20. Nakash RA, Hutton JL, Jørstad-Stein EC, Gates S, Lamb SE. Maximising response to postal questionnaires--a systematic review of randomised trials in health research. BMC Med Res Methodol 2006;6:1-9. 